\title{
Centaurea fenzlii Reichardt Özütünün Antioksidan Özellikleri ve Enzim İnhibisyon Etkisinin Belirlenmesi
}

\author{
Ümit YIRTICI*
}

Kırıkkale Üniversitesi, Săglık Hizmetleri MYO, Tıbbi Hizmetler ve Teknikler Bölümü, 71450, Kırıkkale

\begin{abstract}
$\ddot{O} \mathbf{z}$
$\mathrm{Bu}$ çalışmada Centaurea fenzlii Reichardt bitkisinin antioksidan özellikleri ve çeşitli enzimler üzerine inhibe edici etkisi araştırıldı. Bu amaçla çiçeklenme döneminde toplanan Centaurea fenzlii Reichardt 'in toprak üstü kısımları farklı polariteye sahip çözücülerde maserasyon yöntemi kullanılarak çözüldü ve ekstreleri elde edildi. Çalışmalara metanol ekstresi ile devam edildi. Metanol ekstresinin toplam fenolik ve flavonoid içerikleri sırasıyla, $16,72 \mathrm{mg}$ GAE/g ka ve 173,16 mg KAE/g ka olarak belirlendi. Antioksidan kapasiteleri demir indirgeyici gücü (FRAP) için $0,256 \mathrm{mmol} \mathrm{TE} / \mathrm{g} \mathrm{ka}$, bakır indirgeyici gücü (CUPRAC) için $0,878 \mathrm{mmol} \mathrm{TE} / \mathrm{g} \mathrm{ka}$, ABTS için 0,354 mmol TE/g ka ve DPPH için 0,661 mmol TE/g ka olarak saptandı. Ayrıca, ekstrelerinin kolinesteraz, $\alpha$-amilaz, $\alpha$-glukozidaz ve tirozinaz enzimlerine karşı inhibe edici etkileri de belirlendi. Enzim inhibisyon etkisi sırasıyla, $\alpha$-Glukozidaz için 0,331 mmol AKE/g ka, $\alpha$-Amilaz için 0,354 mmol AKE/g ka, AChE için 0,367 mmol GAE/g ka, BChE için $0,878 \mathrm{mmol} \mathrm{GAE} / \mathrm{g}$ ka ve Tirozinaz için mmol $0,256 \mathrm{KE} / \mathrm{g}$ ka olarak bulundu.
\end{abstract}

Anahtar kelimeler: Centaurea fenzlii Reichardt, Antioksidan, Enzim İnhibisyonu.

\section{The Determination of Antioxidant Properties and Enzyme Inhibition Effect of Centaurea fenzlii Reichardt Extract}

\begin{abstract}
In this study, antioxidant properties of Centaurea fenzlii Reichardt plant and its inhibitory effect on various enzymes were investigated. For this purpose, aerial parts of Centaurea fenzlii Reichardt which collected during flowering time were solved in solvents having different polarity by maceration method and extracts were obtained. The study was continued with methanol extract. Total phenolic and flavonoid contents of the methanol extract were determined as $16.72 \mathrm{mg} \mathrm{GAE} / \mathrm{g} \mathrm{ka}$ and $173.16 \mathrm{mg} \mathrm{KAE} / \mathrm{g}$ ka respectively. Antioxidant capacity was determined as iron reducing power (FRAP) to $0.256 \mathrm{mmol} \mathrm{TE} / \mathrm{g}$ ka, cupper reducing power (CUPRAC) to 0.878 $\mathrm{mmol} \mathrm{TE} / \mathrm{g} \mathrm{ka}$, ABTS to $0.354 \mathrm{mmol} \mathrm{TE} / \mathrm{g} \mathrm{ka}$ and DPPH to $0.661 \mathrm{mmol} \mathrm{TE} / \mathrm{g}$. Additionally, enzyme inhibiting effect of extracts were also determined against to cholinesterase, $\alpha$-amylase, tyrosinase and $\alpha$-glucosidase inhibition. Enzyme inhibitory effects were found for $\alpha$-glucosidase $0.331 \mathrm{mmol} \mathrm{AKE} / \mathrm{g} \mathrm{ka}, \alpha$-amylase $0.354 \mathrm{mmol}$ $\mathrm{AKE} / \mathrm{g} \mathrm{ka}, \mathrm{AChE}$ to $0.367 \mathrm{mmol} \mathrm{GAE} / \mathrm{g} \mathrm{ka}, \mathrm{BChE}$ to $0.878 \mathrm{mmol} \mathrm{GAE} / \mathrm{g}$ ka and tyrosinase for mmol $0.256 \mathrm{KE} / \mathrm{g}$ respectively.
\end{abstract}

Keywords: Centaurea fenzlii Reichardt, Antioxidant, Enzyme Inhibition.

\section{Giriş}

Türkiye'deki en büyük üçüncü cins olan Centaurea n’n 217 türü vardır ve endemizm oranı yaklaşık $\% 68$ 'dir [1]. Centaurea türleri bazı ülkelerde ve Türkiye'de geleneksel olarak apseler, mide ve baş ağrısı, astım, hemoroid, inflamatuar, ürogenital, endokrin hastalıkları, gastrointestinal semptomlar, kardiyovasküler hastalıklar, parazitik, mikrobiyal enfeksiyonlar gibi çeşitli rahatsızlıkları tedavi etmek için kullanılmaktadır [2-9]. Centaurea ile ilgili yapılan bazı çalışmalarda antimikrobiyal, antifungal,

\footnotetext{
* Sorumlu yazar: umityirtici@kku.edu.tr

Geliş Tarihi: 16.11.2018, Kabul Tarihi: 23.01.2019
} 
antiplasmodiyal [8, 10], antiülserojenik [11], antiviral [12], sitotoksik ve apoptotik [13] etkileri belirlenmiştir.

Son yıllarda Alzheimer, Tip II diyabet, Melazma gibi hastalıkları tedavi edici yeni ajanlar bulunmasına yönelik çalışmalar artmıştır. Alzheimer hastalığının 2040 yılında yaklaşık 81,1 milyon insanın etkileyeceği beklenmektedir [14]. Bu hastalığının tedavisinde beyindeki asetilkolin seviyesinin azaltılması, dolayısıyla asetilkolin parçalanmasından sorumlu enzimler olan asetil ve bütiril kolinesterazların inhbisyonu hedeflenmektedir [15].

Tip II diyabetin Alzheimer hastalığına yakalanma riskini artırır. Bu nedenle, hiperglisemiyi kontrol etmede önemli olan $\alpha$-amilaz ve $\alpha$-glukosidazın inhibisyonu ile ilgili çalışmalar önemlidir [16]. Ayrıca Tip II diyabet ciltte hiperpigmentasyona neden olabilir ve tirozinazın inhibisyonu hiperpigmentasyonun önlenmesini sağlayabilir [17].

Bu çalışmada endemik $C$. fenzlii bitkisinin antioksidan kapasitesi, enzim inhibiyonu üzerine etkisi araştırılmıştır. Literatürde, C. fenzlii bitkisinin Tip II diyabet, Azheimer hastalığı ve hiperpigmentasyon ile ilgili enzimlere karşı inhibe edici etkisini araştıran bir çalışmaya rastlanmamıştır.

\section{Materyal ve Metot}

\subsection{Bitkilerin toplanması ve ekstre edilmesi}

C. fenzlii Reichardt, Muş-Elazı ̆̆ yolu 7. km, 1270 m yükseklikten toplanmış ve Kırıkkale Üniversitesi Herbaryumunda bir örneği (ADO 3) alınmıştır. Bitki toplandıktan hemen sonra oda sıcaklığında, kuru ve karanlık bir odada hava ile kurutulmuş ve öğütülmüştür.

Ögütülmüş bitki örnekleri sırasıyla hekzan, metanol ile $3 \times 24$ saat olacak şekilde oda sıcaklığında tutularak ekstre edilmiştir. Çözücüler ekstrelerden rotary-evaporatör kullanılarak uçurulmuştur. Metanol ekstrelerinden elde edilen bileşiklerin daha yüksek biyoaktiviteye sahip olmaları nedeniyle çalışmalara metanol ekstresi ile devam edilmiştir [18].

\subsection{Toplam Fenolik ve Flavonoid içeriğin belirlenmesi}

Toplam fenolik içerik 96 kuyucuklu mikroplakada Folin Ciocalteau metodu modifiye edilerek spektrofotometrik olarak ölçülmüştür [19]. Kuyucuklara 187,5 $\mu \mathrm{L}$ distile su, $25 \mu \mathrm{L}$ metanol ekstresi, 12,5 $\mu \mathrm{L}$ Folin Ciocalteau reaktifi (1:9 oranında seyreltilmiş) eklenip karıştırılmıştır. 6 dakika sonra \%20' lik $25 \mu \mathrm{L} \mathrm{Na} \mathrm{CO}_{3}$ uygulanan örnekler 60 dakika karanlıkta oda sicaklığında bekletilip $760 \mathrm{~nm}$ 'de okunmuştur. Standart olarak Gallik asit kullanılmıştır. Ekstrenin fenolik içeriği g kuru ağırlık (ka) başına düşen $\mathrm{mg}$ Gallik asit (mg GAE/g ka) şeklinde ifade edilmiştir.

Toplam flavonoid içerik bazı değişiklikler yapılarak spektrofotometrik olarak 96 kuyucuklu mikroplakada $\mathrm{AlCl}_{3}$ yöntemine göre ölçülmüsştür [20]. Kuyucuklara $100 \mu \mathrm{L}$ ultra saf su, ardından $10 \mu \mathrm{L}$ $\mathrm{NaNO}_{2}$ ve metanol ekstresinin $25 \mu \mathrm{L}$ 'si eklenerek oda sıcaklığında 5 dakika beklemeye bırakılmıştır. Daha sonra $15 \mu \mathrm{L} \% 10 \mathrm{AlCl}_{3}$ eklenmiş ve 6 dakika oda sıcaklığında karanlıkta bekletildikten sonra $1 \mathrm{M}$ $100 \mu \mathrm{L} \mathrm{NaOH}$ ve $50 \mu \mathrm{L}$ ultra saf su eklenmiştir. Absorbans, mikroplaka okuyucusunda $510 \mathrm{~nm}$ 'de köre karşı ölçülmüştür. Standart olarak Kateşin kullanılmıştır. Değerler mg Kateşin eşdeğeri (KAE) g kuru ağırlık olarak ifade edilmiştir (mg KAE/g ka).

\subsection{Antioksidan Kapasitesinin Belirlenmesi}

C. fenzlii metanol ekstresinin antioksidan kapasitesinin belirlenmesi amaciyla, radikal süpürücü etkisi (DPPH ve ABTS) ve indirgeyici güç etkisi (CUPRAC ve FRAP) ölçülmüştür. Radikal süpürücü etkinin belirlenmesi amaciyla, 96 kuyucuklu plakalara $10 \mu \mathrm{L}$ metanol ekstresi ve $190 \mu \mathrm{L}$ DPPH $(\% 0,004)$ solüsyonu eklendikten sonra örnekler 30 dakika, karanlıkta ve oda sıcaklığında bekletilmiştir. 517 nm'de mikroplaka okuyucuda okunmuştur. Standart olarak Troloks kullanılmıştır. Değerler mmol Troloks eşdeğeri (TE) g kuru ağırlık olarak ifade edilmiştir (mmol TE/g ka) [21].

ABTS testi birkaç değişiklik yapılarak mikroplaka yöntemi ile ölçülmüştür [22]. ABTS ${ }^{+}$ çözeltisi, oda sıcaklığında 16 saat boyunca $2,45 \mathrm{mmol} / \mathrm{L}$ potasyum persülfat ile $7 \mathrm{mmol} / \mathrm{L} 2,2$ '-azinobis (3-etilbenzotiazolin-6-sülfonik asit) diamonyum tuzunun reaksiyona sokulmasıyla hazırlanmıştır. Elde edilen çözelti daha sonra etanol ile 1:50 oranında ve $734 \mathrm{~nm}$ 'de $0.70 \pm 0.02$ absorbans olacak şekilde 
seyreltilmiştir. Kuyucuklara $10 \mu \mathrm{L}$ bitki ekstresi ve $190 \mu \mathrm{L}$ ABTS radikal solüsyonu eklendikten sonra 6 dakika oda sıcaklığında bekletilmiştir. Absorbans, mikroplaka okuyucusunda 734 nm'de köre karş1 ölçülmüştür. Standart olarak Troloks kullanılmıştır. Değerler mmol Troloks eşdeğeri (TE) g kuru ağırlık olarak ifade edilmiştir (mmol TE/g ka) [20].

Metanol ekstrenin bakır indirgeyici gücü birkaç küçük değişiklik yapılarak spektrofotometrik olarak 96 kuyucuklu plakada ölçülmüştür [23]. Öncellikle CUPRAC reaktifi; $10 \mathrm{mM} \mathrm{CuCl} 2,7.5 \mathrm{mM}$ neokuproin, $1 \mathrm{M} \mathrm{NH}_{4} \mathrm{Ac}$ (pH 7) tamponu 1:1:1 olacak şekilde taze olarak hazırlanmıştır. Kuyucuklara $175 \mu \mathrm{L}$ CUPRAC reaktifi ve $25 \mu \mathrm{L}$ bitki metanol ekstresi eklendikten sonra örnekler oda sicaklığında 30 dakika bekletilmiş ve $450 \mathrm{~nm}$ ' de okunmuştur. Standart olarak Troloks kullanılmıştır. Ekstrenin CUPRAC aktivitesi mmol Troloks eşdeğeri (TE) g kuru ağırlık olarak ifade edilmiştir (mmol TE/g ka). Metanol ekstresinin demir indirgeyici gücünü ölçmek için öncellikle FRAP reaktifi; $300 \mathrm{mM}$ asetat tamponu (pH 3.6), $20 \mathrm{mM} \mathrm{FeCl} \cdot 6 \mathrm{H}_{2} \mathrm{O}$ ve $10 \mathrm{mM}$ TPTZ, 10:1:1 oranında olacak şekilde taze olarak hazırlanmıştır. Kuyucuklara 12,5 $\mu \mathrm{L}$ metanol ekstresi ve 312,5 $\mu \mathrm{L}$ FRAP reaktifi eklendikten sonra örnekler oda sicaklığında 10 dakika bekletilmiş ve 593 nm' de okunmuştur. Standart olarak Troloks kullanılmıştır. Değerler mmol Troloks eşdeğeri (TE) g kuru ağırlık olarak ifade edilmiştir (mmol TE/g ka) [24].

\subsection{Enzim İnhibisyon Tayini}

Kolinesteraz inhibisyonun tayini için, 96 kuyucuklu plakaya $50 \mu \mathrm{L}$ metanol ekstresi, $125 \mu \mathrm{L}$ 5,5-ditiobis(2-nitrobenzoik) asit (DTNB) ve Tris- $\mathrm{HCl}$ (pH 8.0) tamponunda hazırlamış $25 \mu \mathrm{L}$ asetilkolinesteraz (AChE) veya butilkolinesteraz (BChE) solüsyonu eklenip örnekler $25^{\circ} \mathrm{C}$ 'de 15 dakika inkübe edilmiştir. Kuyucuklara $25 \mu \mathrm{L}$ asetilkolin iodid (ATCI) veya butilkolin klorid (BTCl) solüsyonunun eklenmesiyle reaksiyon başlatılmıştır. Kör olarak enzimsiz örnekler kullanılmıştır. Örnekler ve kör 10 dakika ve 25 ${ }^{\circ} \mathrm{C}$ tutulduktan sonra $405 \mathrm{~nm}$ ' de okunmuştur. Ekstrenin kolinesteraz inhibisyon aktivitesi, g kuru ağırlık başına mmol Galantamin olarak ifade edilmiştir (mmol GAE/g ka) [25].

$\alpha$-Amilaz inhibisyonunun tayini için, 96 kuyucuklu plakaya $25 \mu \mathrm{L}$ metanol ekstresi, sodyum fosfat tamponunda (pH 6.9) hazırlamış $50 \mu \mathrm{L} \alpha$-amilaz solüsyonu eklenip örnekler $37^{\circ} \mathrm{C}$ 'de 10 dakika inkübe edilmiştir. Kuyucuklara $50 \mu \mathrm{L}$ nişasta solüsyonunun eklenmesiyle reaksiyon başlatılmıştır. Kör olarak enzimsiz örnekler kullanılmıştır. Örnekler ve kör 10 dakika ve $37{ }^{\circ} \mathrm{C}$ 'de inkübe edilmiştir. Reaksiyon $25 \mu \mathrm{L} 1 \mathrm{M} \mathrm{HCl}$ eklenerek durdurulmuş ve $100 \mu \mathrm{L}$ potasyum iodid solüsyonu eklenmiştir. Örnekler ve kör 630 nm'de okunmuştur. Ekstrenin $\alpha$-amilaz inhibisyon etkisi, g kuru ağırlık başına mmol Akarboz olarak ifade edilmiştir (mmol AKE/g ka) [25].

$\alpha$-Glukozidaz inhibisyonunun tayini için, 96 kuyucuklu plakaya $50 \mu \mathrm{L}$ metanol ekstresi, $50 \mu \mathrm{L}$ glutation, fosfat tamponunda (pH 6.8) hazırlamış $50 \mu \mathrm{L} \alpha$-glukozidaz solüsyonu ve $50 \mu \mathrm{L} 4$-N-trofenil$\alpha$-D-glucopiranosid (PNPG) eklenip örnekler $37^{\circ} \mathrm{C}$ 'de 15 dakika inkübe edilmiştir. Kör olarak enzimsiz örnekler kullanılmıştır. Reaksiyon $50 \mu \mathrm{L} 0.2 \mathrm{M}$ sodyum karbonat eklenerek durdurulmuştur, örnekler ve kör 400 nm'de okunmuştur. Ekstrelerin $\alpha$-glukozidaz inhibisyon etkisi, g kuru ağırlık başına mmol Akarboz olarak ifade edilmiştir (mmol AKE/g ka) [25].

Tirozinaz inhibisyonunun tayini için, 96 kuyucuklu plakaya $25 \mu \mathrm{L}$ metanol ekstresi, $100 \mu \mathrm{L}$ fosfat tamponu (pH 6.8) ve $40 \mu \mathrm{L}$ tirozinaz solüsyonu eklenip örnekler $25{ }^{\circ} \mathrm{C}$ 'de 15 dakika inkübe edilmiş̧tir. Kuyucuklara $40 \mu \mathrm{L}$ L-DOPA solüsyonunun eklenmesiyle reaksiyon başlatılmıştır. Kör olarak enzimsiz örnekler kullanılmıştır. Örnekler ve kör 10 dakika ve $25{ }^{\circ} \mathrm{C}$ tutulduktan sonra $492 \mathrm{~nm}$ 'de okunmuştur. Ekstrelerin tirozinaz inhibisyon aktivitesi, g kuru ağırlık başına mmol kojik asit olarak ifade edilmiştir (mmol KE/g ka) [25].

\section{5. İstatistiksel Analiz}

Çalışmada tüm deneyler üç tekrar olacak şekilde yapılmıştır. Çalışmaya ait tanımlayıcı istatistik verileri (Ortalama \pm Standart Sapma (Ort. $\pm S)$ ) tablolar halinde gösterilmiştir.

\section{Bulgular ve Tartışma}

C. fenzlii metanol ekstresinin toplam fenolik ve flavonoid içeriği tayin edilmiştir (Tablo 1). 
Tablo 1. C. fenzlii metanol ekstresinin toplam fenolik ve flavonoid içeriği

\begin{tabular}{lc}
\hline Yöntem & Metanol Ekstresi $($ Ort. $\pm \boldsymbol{S})$ \\
\hline Toplam fenolik içerik (mg GAE/g ka) & $16.72 \pm 0,01$ \\
Toplam flavonoid içerik (mg KAE/g ka) & $173,16 \pm 0,01$ \\
\hline
\end{tabular}

C. fenzlii metanol ekstresi için toplam fenolik içerik 16,72 mg GAE/g ka olarak bulunmuştur. Centaurea cinsine ait diğer türlerle yapılan çalışmalarda farklı sonuçlar elde edilmiştir [26-28]. Bu sonuçlar Centaurea türlerindeki toplam fenolik içeriğin değişkenlikler gösterebileceğini ortaya koymaktadır. Toplam fenolik içerik antioksidan aktivite için önemlidir. Çünkü fenolik içerik arttıkça ekstrenin, reaktif serbest radikalleri veya primer oksidanları gidebilmesi o kadar güçlü olur ve insan sağlığı için önemli hale gelir [18].

Toplam flavonoid içerik ise 173,16 mg KAE/g ka şeklinde bulunmuştur. $C$. fenzlii bitkisinden elde edilen toplam flavonoid içerik benzer ve farklı standartlar kullanılan çalışmalara göre daha yüksek tespit edilmiştir $[9,10,28]$. Chigayo ve arkadaşları flavonoidlerin hastalıklarla mücadele önemli olduklarını ve yapılarına bağlı olarak da antioksidan olarak kullanılabileceklerini, fenolik bileşiklerle birleştiklerinde ise yüksek antioksidan aktivite gösterebileceklerini bildirilmişlerdir [18]. Bu yüzden yüksek flavonoid içerik farmasötik açıdan önemlidir.

Bu çalışmada C. fenzlii metanol ekstresinin antioksidan kapasitesi DPPH, ABTS, FRAP, CUPRAC testleri kullanılarak belirlenmiştir (Tablo 2).

Tablo 2. C. fenzlii metanol ekstresinin radikal giderici ve indirgeyici gücü

\begin{tabular}{lc}
\hline Yöntem (mmol TE/g ka) & Metanol Ekstresi $(\boldsymbol{O r t .} \pm \boldsymbol{S})$ \\
\hline DPPH & $0,661 \pm 0,01$ \\
ABTS & $0,354 \pm 0,02$ \\
CUPRAC & $0,878 \pm 0,08$ \\
FRAP & $0,256 \pm 0,03$ \\
\hline
\end{tabular}

DPPH testi radikal giderme aktivitesini ölçmek için yaygın olarak kullanılan bir antioksidan testtir [29]. C. fenzlii için DPPH radikal giderme aktivitesi $0,661 \mathrm{mmol}$ TE/g ka olarak bulunmuştur. Elde edilen bu sonuç DPPH radikal giderme aktivitesi araştırılan birçok Centaurea türüne göre yüksektir $[28,30]$. DPPH radikali giderme aktivitesinin fenolik içerikle ilişkisi olduğu söyleyen birçok çalışma bulunmaktadır [29, 31, 32].

ABTS testi de yine antioksidan aktivitesini belirlemek için yaygın olarak kullanılan başka bir testtir. C. fenzlii metanol ekstresi için ABTS radikal giderme aktivitesi 0,345 $\mathrm{mmol}$ TE/g ka olarak bulunmuştur.

Bu değer farklı Centaurea türleri ile ilgili bazı çalışmalara göre daha düşük bulunmuştur $[4,33]$. Genel olarak ABTS testinin, hidrofilik, lipofilik ve pigment oranı yüksek antioksidan bileşiklere uygulandığında DPPH testine göre üstün olduğu kabul edilmektedir [34]. Bu yüzden metanol ekstresinde bu tür antioksidan bileşiklerin daha az bulunduğu söylenebilir.

Metanol ekstresinin indirgenme gücünü belirlemek için CUPRAC ve FRAP yöntemleri yapılmıştır. FRAP yöntemi, çalış1lan örneğin ferrik tripiridiltriazini $\left(\mathrm{Fe}^{+3}-\mathrm{TPTZ}\right)$ ferröz tripiridiltriazine $\left(\mathrm{Fe}^{+2}-\right.$ TPTZ) indirgeme potansiyelini ölçerken, CUPRAC, kuprik-neokuprinin $\left(\mathrm{Cu}^{+2}-\mathrm{Neokuprin}\right)$ kuprözneokuprine $\left(\mathrm{Cu}^{+1}\right.$-Neokuprin) indirgeme potansiyelini ölçer. C. fenzlii için CUPRAC değeri 0,878 mmol TE/g ka,, FRAP değeri 0,256 mmol TE/g ka olarak bulunmuştur. Çalışan türün hem demir hem de bakır indirgeme gücü açısından etkin olduğu söylenebilir [28, 30, 35]. FRAP testi, fizyolojik pH' dan uzak asidik bir pH 3.6'da yapılırken, CUPRAC testi $\mathrm{pH}$ 7.0' da gerçekleştirilir ve fizyolojik koşullara daha uygundur [36].

C. fenzlii metanol ekstresinin 4 farklı enzime karşı inhibe edici etkisi belirlenmiştir (Tablo 3). 
Tablo 3. C. fenzlii metanol ekstresinin enzimleri inhibe edici aktivitesi

\begin{tabular}{lc}
\hline Yöntem & Metanol Ekstresi $($ Ort. $\pm \boldsymbol{S})$ \\
\hline$\alpha$-Glukozidaz (mmol AKE/g ka) & $0,331 \pm 0,01$ \\
$\alpha$-Amilaz (mmol AKE/g ka) & $0,354 \pm 0,06$ \\
AChE (mmol GAE/g ka) & $0,367 \pm 0,02$ \\
BChE (mmol GAE/g ka) & $0,878 \pm 0,01$ \\
Tirozinaz (mmol KE/g ka) & $0,256 \pm 0,00$ \\
\hline
\end{tabular}

Asetilkolin bilişsel işlevlerde, özellikle bellekte rol oynar. AChE, bir nörotransmitter olan asetilkolini parçalayan bir enzimdir. Kolinerjik nöronların dejenerasyonu asetilkolinin azalması ile karakterize edilir ve alzheimer hastalığı ile ilişkilidir [37]. AChE inhibitörleri, asetilkolinin hidrolizini önler, böylece beyindeki seviyesini arttırır. BChE, beyinde sinirsel iletimde görev yapan bir başka kolinesteraz enzimidir. Alzheimer hastalığının geç evresinde BChE aktivitesinin \%40-90 arasında arttığı belirlenmiştir [38]. Aynı zamanda senil plak oluşumunun ilk evresinde beta-amiloid agregasyonunda yüksek düzeyde $\mathrm{BChE}$ aktivitesi bildirilmiştir [39]. BChE inhibisyonu, beta-amiloid protein seviyelerini düşürdüğü ve farelerde öğrenme performansını artırdığı gösterilmiştir [40]. C. fenzlii metanol ekstresinin AChE için inhibe edici etkisi 0,367 mmol GAE/g ka, BChE için inhibe edici etkisi ise 1,496 mmol GAE/g ka olarak bulunmuştur. Elde edilen sonuçlar diğer Centaurea cinsine ait yapılan çalışmalarla benzerlik göstermektedir [35, 41].

Diyabet kronik hiperglisemi ile karakterizedir ve tüm dünyada önemli bir sağlık problemi haline gelmiştir. Kanda sürekli yüksek glukoz seviyesi, kardiyovasküler hastalıklara, nöropatiye, retinopatiye, nefropatiye ve diğer işlev bozukluklarına yol açar. Günümüzde kullanılan hipoglisemik ilaçlar, serum glikoz seviyesini normale döndürmeyi başarmakta ancak gastrointestinal rahatsızlıklar neden olmaktadır. Bu nedenle, $\alpha$-Amilaz ve $\alpha$-Glukozidaz'ı inhibe eden ve yan etkisi olmayan etkili terapötik ajanların bulunması önemlidir [42].

C. fenzlii metanol ekstresinin $\alpha$-Amilaz için inhibe edici etkisi 0,614 mmol AKE/g ka, $\alpha$ Glukozidaz için inhibe edici etkisi 0,331 $\mathrm{mmol} \mathrm{AKE/g} \mathrm{ka} \mathrm{bulunmuştur.} \mathrm{Genel} \mathrm{olarak} \alpha$-Amilazı inhibe edici etkisi için çıkan sonuç literatürle benzerdir, $\alpha$-Glukozidazı inhibe edici etkisi ise bazı çalışmalara göre daha düşük bazı çalışmalara göre daha yüksek bulunmuştur [35, 43].

C. fenzlii metanol ekstresinin Tirozinaz enzimini inhibe edici etkisi 0,952 $\mathrm{mmol} \mathrm{KE} / \mathrm{g}$ ka olarak bulunmuştur. Benzer türlerle yapılan çalışmalar göre $C$. fenzlii bitkisinin tirozinaz enziminin inhibisyonunda daha etkili olduğu söylenebilir [35, 43].

Tirozinaz, UV ışığının önlenmesine yardımcı olan melanin pigmentinin üretimini katalizleyen bir enzimdir. Fazla olması hiperpigmentasyona ve Parkinson hastalığı gibi nörodejeneratif hastalıklara yol açabilir. Tirozinaz enzim inhibitörleri, cilt kanseri ve melanin birikimi ile ilişkili diğer dermatolojik hastalıkların tedavisinde kullanılabilir [44].

Oksidatif stres, diyabet tip II ve Alzheimer hastalığı dahil olmak üzere birçok hastalık için ana patolojik tetikleyici olarak kabul edilmektedir. Sonuç olarak, antioksidanlar oksidatif stres eylemini ve oluşumunu engellemek için terapötik araçlar olarak düşünülmektedir [42].

\section{Sonuç ve Öneriler}

Bu araştırmada, endemik C. fenzlii metanol ekstresinin antioksidan özellikleri ve farklı enzimleri inhibe edici etkisi araştırılmıştır. $C$. fenzlii bitkisinin diğer Centaurea türlerine göre toplam flavonoid içeriğinin daha yüksek, fenolik içeriğinin ise araştırılan diğer türlere yakın olduğu belirlenmiştir. DPPH testi ile radikal giderme aktivitesinin, CUPRAC ve FRAP testleri ile de indirme gücü açısından daha etkin fakat ABTS radikal giderme gücü açısından ise daha az olduğu tespit edilmiştir. AChE, $\mathrm{BChE}$ ve $\alpha$-Amilazı enzimleri ile ilgili olarak diğer Centaurea türlerine göre benzer etkiler görülse de $\alpha$-Glukozidaz ve Tirozinaz enzimleri üzerine inhibe edici etkisi yüksek bulunmuştur. C. fenzlii bitkisinin antioksidan özelliklerinin ve farklı enzimleri inhibe edici etkisinin belirlenmesiyle ilgili ilk çalışma olması nedeniyle literatüre katkı sağlayacağı düşünülmektedir. 


\section{Teşekkür}

$\mathrm{Bu}$ çalışma Kırıkkale Üniversitesi Bilimsel Araştırma Projeleri Koordinatörlüğü tarafından desteklenmiştir (2015/113 No'lu Proje).

\section{Kaynaklar}

[1] Bona M. 2016. Centaurea amanosensis (Asteraceae), a new species from Turkey. Plant Biosystems, 150 (5): 1083-1086.

[2] Baharfar R., Khalilzadeh M.A., Gheibi S., Jazayeri O., Azimi R., Tajbakhsh M. 2009. Antioxidant and antibacterial activities of the methanolic extract of Centaurea zuvandica Sosn. Iran JOC, 3: 172-177.

[3] Koca U., Suntar I.P., Keles H., Yesilada E., Akkol E.K. 2009. In vivo anti-inflammatory and wound healing activities of Centaurea iberica Trev. ex Spreng. J Ethnopharmacol, 126 (3): 551-556.

[4] Kose Y.B., Iscan G., Goger F., Akalin G., Demirci B., Baser K.H. 2016. Chemical Composition and Biological Activity of Centaurea baseri: New Species from Turkey. Chem Biodivers, 13 (10): 1369-1379.

[5] Akkol E.K., Arif R., Ergun F., Yesilada E. 2009. Sesquiterpene lactones with antinociceptive and antipyretic activity from two Centaurea species. J Ethnopharmacol, 122 (2): 210-215.

[6] Aktumsek A., Zengin G., Guler G.O., Cakmak Y.S., Duran A. 2011. Screening for in vitro antioxidant properties and fatty acid profiles of five Centaurea L. species from Turkey flora. Food Chem Toxicol, 49 (11): 2914-2920.

[7] Dumlu M.U., Gurkan E. 2006. A new active compound from Centaurea species. Z Naturforsch C, 61 (1-2): 44-46.

[8] Karamenderes C., Khan S., Tekwani B.L., Jacob M.R., Khan I.A. 2006. Antiprotozoal and antimicrobial activities of Centaurea species growing in Turkey. Pharmaceutical Biology, 44 (7): 534-539.

[9] Albayrak S., Atasagun B., Aksoy A. 2017. Comparison of phenolic components and biological activities of two Centaurea sp. obtained by three extraction techniques. Asian Pac J Trop Med, 10 (6): 599-606.

[10] Ozsoy N., Kultur S., Yilmaz-Ozden T., Celik B.O., Can A., Melikoglu G. 2015. Antioxidant, AntiInflammatory, Acetylcholinesterase Inhibitory and Antimicrobial Activities of Turkish Endemic Centaurea antiochia var-Praealta. Journal of Food Biochemistry, 39 (6): 771-776.

[11] Gurbuz I., Yesilada E. 2007. Evaluation of the anti-ulcerogenic effect of sesquiterpene lactones from Centaurea solstitialis L. ssp. solstitialis by using various in vivo and biochemical techniques. J Ethnopharmacol, 112 (2): 284-291.

[12] Ozcelik B., Gurbuz I., Karaoglu T., Yesilada E. 2009. Antiviral and antimicrobial activities of three sesquiterpene lactones from Centaurea solstitialis L. ssp. solstitialis. Microbiol Res, 164 (5): 545 552.

[13] Yirtici U., Goger F., Sarimahmut M., Ergene A. 2017. Cytotoxic and apoptotic effects of endemic Centaurea fenzlii Reichardt on the MCF-7 breast cancer cell line. Turkish Journal of Biology, 41 (2): 370-377.

[14] Dhouafli Z., Rigacci S., Leri M., Bucciantini M., Mahjoub B., Tounsi M.S., Wannes W.A., Stefani M., Hayouni E.A. 2018. Screening for amyloid- $\beta$ aggregation inhibitor and neuronal toxicity of eight Tunisian medicinal plants. Industrial Crops and Products, 111: 823-833.

[15] Li Q., Tu Y., Zhu C., Luo W., Huang W., Liu W., Li Y. 2017. Cholinesterase, $\beta$-amyloid aggregation inhibitory and antioxidant capacities of Chinese medicinal plants. Industrial Crops and Products, 108: 512-519.

[16] Li W., Risacher S.L., Gao S., Boehm S.L., Elmendorf J.S., Saykin A.J. 2018. Type 2 diabetes mellitus and cerebrospinal fluid Alzheimer's disease biomarker amyloid beta1-42 in Alzheimer's Disease Neuroimaging Initiative participants. Alzheimers Dement (Amst), 10: 94-98.

[17] Mendes A.L., Miot H.A., Haddad V.J. 2017. Diabetes mellitus and the skin. An Bras Dermatol, 92 (1): 8-20. 
[18] Chigayo K., Mojapelo P.E.L., Mnyakeni-Moleele S., Misihairabgwi J.M. 2016. Phytochemical and antioxidant properties of different solvent extracts of Kirkia wilmsii tubers. Asian Pacific Journal of Tropical Biomedicine, 6 (12): 1037-1043.

[19] Slinkard K., Singleton V.L. 1977. Total Phenol Analysis: Automation and Comparison with Manual Methods. American Journal of Enology and Viticulture, 28 (1): 49-55.

[20] Zenão S., Aires A., Dias C., Saavedra M.J., Fernandes C. 2017. Antibacterial potential of Urtica dioica and Lavandula angustifolia extracts against methicillin resistant Staphylococcus aureus isolated from diabetic foot ulcers. Journal of Herbal Medicine, 10: 53-58.

[21] Fitsiou E., Mitropoulou G., Spyridopoulou K., Tiptiri-Kourpeti A., Vamvakias M., Bardouki H., Panayiotidis M., Galanis A., Kourkoutas Y., Chlichlia K., Pappa A. 2016. Phytochemical Profile and Evaluation of the Biological Activities of Essential Oils Derived from the Greek Aromatic Plant Species Ocimum basilicum, Mentha spicata, Pimpinella anisum and Fortunella margarita. Molecules, 21 (8): 1069.

[22] Auzanneau N., Weber P., Kosinska-Cagnazzo A., Andlauer W. 2018. Bioactive compounds and antioxidant capacity of Lonicera caerulea berries: Comparison of seven cultivars over three harvesting years. Journal of Food Composition and Analysis, 66: 81-89.

[23] Reşat A., Güçlü K., Özyürek M., Saliha Esin K., Erça E. 2006. The cupric ion reducing antioxidant capacity and polyphenolic content of some herbal teas. International Journal of Food Sciences and Nutrition, 57 (5/6): 292.

[24] Jiménez N., Carrillo-Hormaza L., Pujol A., Álzate F., Osorio E., Lara-Guzman O. 2015. Antioxidant capacity and phenolic content of commonly used anti-inflammatory medicinal plants in Colombia. Industrial Crops and Products, 70: 272-279.

[25] Sarikurkcu C., Kirkan B., Ozer M.S., Ceylan O., Atilgan N., Cengiz M., Tepe B. 2018. Chemical characterization and biological activity of Onosma gigantea extracts. Industrial Crops and Products, 115: 323-329.

[26] Shahrbandy K. Hosseinzadeh R. 2007. In vitro Antioxidant Activity of Polygonium hyrcanicum, Centaurea depressa, Sambucus ebutus, Mentha spicata and Phytolacca americana. Pakistan Journal of Biological Sciences, 10 (4): 637-640.

[27] Erol-Dayi Ö., Pekmez M., Bona M., Aras-Perk A., Arda N. 2011. Total Phenolic Contents, Antioxidant Activities Cytotoxicity of Three Centaurea Species: C. calcitrapa subsp. calcitrapa, C. ptosimopappa, C. spicata. Free Radicals and Antioxidants, 1 (2): 31-36.

[28] Ayaz F.A., Ozcan M., Kurt A., Karayigit B., Ozogul Y., Glew R., Ozogul F. 2017. Fatty acid composition and antioxidant capacity of cypselas in Centaurea s.l. taxa (Asteraceae, Cardueae) from NE Anatolia. South African Journal of Botany, 112: 474-482.

[29] Loganayaki N., Siddhuraju P.Manian S. 2013. Antioxidant activity and free radical scavenging capacity of phenolic extracts from Helicteres isora L. and Ceiba pentandra L. J Food Sci Technol, 50 (4): 687-695.

[30] Kenny O., Smyth T.J., Walsh D., Kelleher C.T., Hewage C.M., Brunton N.P. 2014. Investigating the potential of under-utilised plants from the Asteraceae family as a source of natural antimicrobial and antioxidant extracts. Food Chem, 161: 79-86.

[31] Piluzza G., Bullitta S. 2011. Correlations between phenolic content and antioxidant properties in twenty-four plant species of traditional ethnoveterinary use in the Mediterranean area. Pharm Biol, 49 (3): 240-247.

[32] Sadeghi Z., Valizadeh J., Azyzian Shermeh O., Akaberi M. 2015. Antioxidant activity and total phenolic content of Boerhavia elegans (choisy) grown in Baluchestan, Iran. Avicenna J Phytomed, 5 (1): 1-9.

[33] Erel S.B., Demir S., Nalbantsoy A., Ballar P., Khan S., Yavasoglu N.U., Karaalp C. 2014. Bioactivity screening of five Centaurea species and in vivo anti-inflammatory activity of C. athoa. Pharm Biol, 52 (6): 775-781.

[34] Floegel A., Kim D.O., Chung S. J., Koo S.I., Chun O.K. 2011. Comparison of ABTS/DPPH assays to measure antioxidant capacity in popular antioxidant-rich US foods. Journal of Food Composition and Analysis, 24 (7): 1043-1048.

[35] Zengin G., Bulut G., Mollica A., Nancy Picot-Allain C.M., Mahomoodally M.F. 2018. In vitro and in silico evaluation of Centaurea saligna (K.Koch) Wagenitz-An endemic folk medicinal plant. Comput Biol Chem, 73: 120-126. 
[36] Bessada S.M.P., Barreira J.C.M., Oliveira M.B.P.P. 2015. Asteraceae species with most prominent bioactivity and their potential applications: A review. Industrial Crops and Products, 76: 604-615.

[37] Sarikurkcu C., Uren M.C., Tepe B., Cengiz M., Kocak M.S. 2015. Phlomis armeniaca: Phenolic compounds, enzyme inhibitory and antioxidant activities. Industrial Crops and Products, 78: 95101.

[38] Darvesh S. 2016. Butyrylcholinesterase as a Diagnostic and Therapeutic Target for Alzheimer's Disease. Current Alzheimer Research, 13 (10): 1173-1177.

[39] Reid G.A. Darvesh S. 2015. Butyrylcholinesterase-knockout reduces brain deposition of fibrillar beta-amyloid in an Alzheimer mouse model. Neuroscience, 298: 424-435.

[40] Greig N.H., Utsuki T., Ingram D.K., Wang Y., Pepeu G., Scali C., Yu Q.S., Mamczarz J., Holloway H.W., Giordano T., Chen D., Furukawa K., Sambamurti K., Brossi A., Lahiri D.K. 2005. Selective butyrylcholinesterase inhibition elevates brain acetylcholine, augments learning and lowers Alzheimer beta-amyloid peptide in rodent. Proc Natl Acad Sci U S A, 102 (47): 17213-17218.

[41] Aktumsek A., Zengin G., Guler G.O., Cakmak Y.S., Duran A. 2013. Antioxidant potentials and anticholinesterase activities of methanolic and aqueous extracts of three endemic Centaurea $\mathrm{L}$. species. Food Chem Toxicol, 55: 290-296.

[42] Liu S., Ai Z., Qu F., Chen Y., Ni D. 2017. Effect of steeping temperature on antioxidant and inhibitory activities of green tea extracts against alpha-amylase, alpha-glucosidase and intestinal glucose uptake. Food Chem, 234: 168-173.

[43] Zengin G., Zheleva-Dimitrova D., Gevrenova R., Nedialkov P., Mocan A., Ciric A., Glamoclija J., Sokovic M., Aktumsek A., Mahomoodally M.F. 2018. Identification of phenolic components via LC-MS analysis and biological activities of two Centaurea species: C. drabifolia subsp. drabifolia and C. lycopifolia. J Pharm Biomed Anal, 149: 436-441.

[44] Aghraz A., Goncalves S., Rodriguez-Solana R., Dra L.A., Di Stefano V., Dugo G., Cicero N., Larhsini M., Markouk M., Romano A. 2018. Antioxidant activity and enzymes inhibitory properties of several extracts from two Moroccan Asteraceae species. South African Journal of Botany, 118: 58-64. 